\title{
HVMANITAS
}

\section{A atenção de Varrão às palavras no livro III do De re rustica}

Autor(es): Trevizam, Matheus

Publicado por: Faculdade de Letras da Universidade de Coimbra, Instituto de Estudos
Clássicos

URL

persistente:

DOI: $\quad$ DOI:http://dx.doi.org/10.14195/2183-1718_63_20

Accessed : $\quad$ 26-Apr-2023 09:16:57

A navegação consulta e descarregamento dos títulos inseridos nas Bibliotecas Digitais UC Digitalis, UC Pombalina e UC Impactum, pressupõem a aceitação plena e sem reservas dos Termos e Condições de Uso destas Bibliotecas Digitais, disponíveis em https://digitalis.uc.pt/pt-pt/termos.

Conforme exposto nos referidos Termos e Condições de Uso, o descarregamento de títulos de acesso restrito requer uma licença válida de autorização devendo o utilizador aceder ao(s) documento(s) a partir de um endereço de IP da instituição detentora da supramencionada licença.

Ao utilizador é apenas permitido o descarregamento para uso pessoal, pelo que o emprego do(s) título(s) descarregado(s) para outro fim, designadamente comercial, carece de autorização do respetivo autor ou editor da obra.

Na medida em que todas as obras da UC Digitalis se encontram protegidas pelo Código do Direito de Autor e Direitos Conexos e demais legislação aplicável, toda a cópia, parcial ou total, deste documento, nos casos em que é legalmente admitida, deverá conter ou fazer-se acompanhar por este aviso. 
humanitas

Vol. LXIII

2011 


\title{
A ATENÇÃo DE VARRÃo Às PALAVRAS NO LIVRO III DO DE RE RUSTICA
}

\author{
Matheus Trevizam ${ }^{1}$ \\ matheustrevizam2000@yahoo.com.br
}

\section{Resumo}

A partir da seleção de passagens do De re rustica III, de Varrão reatino, propomos um olhar para o tema da atenção do autor às palavras, como isso entendendo, até, a integração de ofícios "gramaticais" nas páginas desta antiga obra romana de "agronomia".

Palavras-chave: Varrão de Reate; De re rustica III; palavra; Gramática antiga; comicidade.

\section{Abstract}

Starting from the selection of excerpts of Varro Reatinus' De re rustica III, we propose to cast a glance at the theme of this author's attention to the word, understanding by that the integration of "grammatical" tasks into the pages of this ancient Roman work of "agronomy".

Keywords: Varro of Reate; De re rustica III; word; ancient Grammar; comical effects.

${ }^{1}$ Professor Adjunto Doutor da Faculdade de Letras da Universidade Federal de Minas Gerais, Belo Horizonte/ Brasil (agradeço ao prof. Dr. Marcos Aurélio Pereira - IEL-UNICAMP -, pela generosa cessão de material bibliográfico referente às etimologias varronianas, e à profa. Dra. Tereza Virgínia Barbosa - FALEUFMG -, pela criação de condições favoráveis à escrita deste artigo). Nosso trabalho maior de pesquisa sobre Varrão, em sua fase inicial - 2008-2010 -, contou com o apoio da PRPq. da Universidade Federal de Minas Gerais, através do "Programa de auxílio para a pesquisa dos doutores recém-contratados". 


\section{a. Introdução}

A partir de uma instigante indicação de Heurgon, abordaremos não servilmente, ${ }^{2}$ ao longo do artigo que segue, o tema da atenção de Varrão reatino às palavras, no livro III de seu De re rustica. ${ }^{3}$ Por essa expressão, deve-se entender não o mero cumprimento de um requisito mínimo para qualquer escritor, ou seja, o cuidar de fazer-se eficazmente comunicativo pela via da adequada seleção e articulação sintática (e textual) dos itens lexicais no corpo de uma obra qualquer, mas, antes, o gesto de "debruçarse" pausado sobre certas palavras com fins específicos a- de oferecer-lhes definições esclarecedoras dos sentidos, b- dar-lhes a etimologia, à maneira antiga, ${ }^{4} \mathrm{c}$ - selecioná-las para resultarem em produtivos efeitos de trocadilho e humor e d- "traduzi-las" para o outro grande idioma de interface no mundo romano clássico (o grego).

Com efeito, a leitura corrida de todo o De re rustica (sem excluir a parte desta obra de que nos ocupamos aqui com maior especificidade) mostra-nos com muita frequência a face do polígrafo e erudito, capaz não só de integrar a um texto técnico de agropecuária saberes atinentes a áreas distintas do saber humano, mas ainda, como explicamos numa ocasião diversa, ${ }^{5}$ até procedimentos epistemológicos cuja originária zona de procedência se furta aos limites das práticas rústicas. E, sabemos, o conjunto da produção de Varrão foi vasto e matizado, como comprova a notícia jeronimiana de seus, talvez, seiscentos livros, ${ }^{6}$ em cobertura a tópicos tão

${ }^{2}$ Como se verá a seguir, nossas categorias de análise não se identificarão, de todo, com as mesmas de Heurgon no tocante ao privilegiado tratamento varroniano dos vocábulos (cf. infra nota 2 ).

${ }^{3}$ Heurgon 1950: 70 : «Dans les 'Res Rusticae', en tout cas, sa curiosité philologique ne l'abandonne jamais: son soin constant est de définir les termes, d'en préciser l'explication, de signaler les emprunts au grec, de rappeler les survivances de l'ancienne langue ».

${ }^{4}$ A respeito do estatuto epistemológico particular da etimologia no mundo antigo e, especialmente, em Varrão, veja-se Blank 2008: 49-73.

5 Trevizam 2009: 94-95: "Quais seriam, pois, os recursos de seu saber 'gramatical' que Varrão põe a serviço dos leitores, evidentemente, dado o conteúdo geral do livro II do 'De re rustica', visando a esclarecer-lhes pontos variados dos assuntos pecuários? De que modo esses recursos, em princípio enraizados num outro discurso, articulam-se funcionalmente com os mesmos temas rústicos para gerar-lhes o aclaramento?"

${ }^{6}$ Codoñer 2007: 766: "San Jerónimo, en su afán de compararlo con Oríge- 
díspares quanto a linguagem, a própria "agronomia", a história, a filosofia, a geografia, o direito, a retórica, a dialética, a geometria, a aritmética, o teatro...

A conjunção desses dois dados fundamentais, então, aponta para o influxo geral dos ricos saberes varronianos num tratado específico como aquele sobre o qual nos detemos agora, além do efeito de sentidos que se poderia chamar de "solidariedade" entre as tantas compartimentações teóricas, jamais de todo estanques, da obra poligráfica do autor. Particularmente, como escolhemos no presente tratar de alguns olhares varronianos para a palavra no livro III do De re rustica, claro está que o principal domínio especulativo-outro a adentrar as páginas rústicas desta parte dos diálogos corresponde à Gramática, segundo sua antiga delimitação, por exemplo, na Téchnē Grammatichē de Dionísio Trácio (circa 100 a.C.):

"Escreve Dionísio: ‘A gramática é o conhecimento prático do uso linguístico comum aos poetas e aos prosadores. Divide-se em seis partes: primeira, leitura exata (em voz alta), com a devida atenção à prosódia; segunda, explicação das expressões literárias das obras (grifo nosso); terceira, preparo de notas sobre fraseologia e temática; quarta, descobrimento das etimologias (grifo nosso); quinta, determinação das regularidades analógicas; sexta, crítica das composições literárias, que é a parte mais nobre da gramática'."7

Quanto à etimologia, tratou-se de uma prática "gramatical” de grande prestígio na Antiguidade, tendo-se originado das especulações de filósofos como os Estoicos (mas não só). ${ }^{8}$ Para esses, de início, teria havido grande nexo de parecença entre os objetos designados e os termos a eles aplicados para nomeá-los "naturalmente", de modo que, mesmo, chegaram a ter na onomatopeia um princípio básico da construção vocabular. ${ }^{9}$ Assim, "etimo-

nes, estableció un catálogo de sus obras que ha llegado a nosotros a partir de su redacción en una carta a Paula que sufrió muchos avatares de transmisión".

${ }^{7}$ Apud Robins 1983: 24-25.

${ }^{8}$ Para uma visão mais ampla dos praticantes e dos respectivos significados da etimologia no mundo greco-romano, veja-se Trevizam 2002-2003: 179-188.

${ }^{9}$ Lyons 1979: 4-5: "O termo técnico empregado para palavras que pertencem a essas duas categorias, ainda usado neste sentido, era 'onomatopeia'. É simplesmente a palavra grega que significa 'criação de nomes'. O fato de os gramáticos restringirem o seu uso a palavras que 'imitam' os sons que elas denotam reflete a concepção dos 'naturalistas' gregos - especialmente dos filósofos estoicos 
logizar", à maneira estoica ou semelhante, sobretudo significou, no mundo greco-romano, aproximar-se dos "sentidos verdadeiros" dos termos, anteriores à sua gradual "deturpação" pelo uso quotidiano. ${ }^{10}$

Ainda, uma vez que a erudição varroniana também cobriu a crítica dramática, representada por uma obra perdida como as Quaestiones Plautinae, inferimos, apesar da óbvia impossibilidade de acessarmos diretamente o teor de seus comentários sobre a comédia antiga, que o reatino deve terse dado conta da presença dos jogos de palavras (e da significação expressiva dos nomes próprios das personagens a interagirem) enquanto um dos principais recursos disponíveis para gerar comicidade nos discursos. ${ }^{11} \mathrm{Em}$ Plauto, na verdade, abundam exemplos da recorrência a trocadilhos com fins da ridicularização de personagens e situações: a título de exemplo, poder-se-ia citar, conforme oportunamente comentada por Paratore, ${ }^{12}$ a passagem da Aulularia (v. 637) em que, interrogado pelo escravo Estróbilo a respeito de seus desejos quanto a si (de fato, apenas correspondentes a anseios de recobrar a marmitinha cheia de ouro identificada com todo o patrimônio familiar em jogo), o velho Euclião responde sucinto com o imperativo latino pone [“depõe", "deposita”, “deixa”(-a)].

Contudo, em harmonia com o caráter malicioso da personagem do escravo astuto que "encarna" nesta peça, Estróbilo simula interpretar a resposta de Euclião com o sentido contextualmente obsceno do advérbio

- de que tais palavras formam a série fundamental de 'nomes' dos quais evolui a língua. A relação fundamental entre uma palavra e o seu significado era a de "dar nome' (nominação); e originalmente as palavras eram 'imitativas' das coisas que elas nomeavam. As palavras onomatopaicas formavam o núcleo do vocabulário".

${ }^{10}$ Varrón 1990: 33-34 (do estudo introdutório de Manuel-Antonio Marcos Casquero): "Resulta esclarecedorque el estoicismo utilizara el término 'etimología', es decir, 'significado verdadero'. En efecto, para un estoico la auténtica verdad de una palabra consiste en la correspondencia natural y necesaria entre su significante y su significado, entre el nombre y el objeto designado; bastará desentrañar el origen de la palabra para descubrir la esencia última de lo que designa”.

${ }^{11}$ Claro está que, como comprova a literatura antiga, não só no teatro ocorriam efeitos cômicos derivados da antroponímia "zoológica". Nas Verrinas de Cícero, assim, o arpinate evoca com alguma frequência a identidade morfológica entre o nome do réu e o substantivo comum uerres ("porco por castrar" em latim). A esse respeito, cf. cuidada discussão de Poccetti 2009: 131 - acessado pela internet em 20/ 01/ 2011 <http://www.unicaen.fr/services/puc/ecrire/preprints/ preprint0082009.pdf. $>$.

${ }^{12}$ Apud Plauto 2004: 312. 
"por detrás" (de idêntica morfologia na língua latina!), remetendo-nos a óbvias conotações sexuais e que envolvem não a marmitinha, mas o ato passivo do ponto de vista do lesado.

Sobre a exploração dramática da comicidade dos nomes próprios, enfim, trata-se de um aspecto dos mais discutidos pelos comentadores dos diálogos rústicos de Varrão, e que se encontra documentado, pelo menos, desde as práticas da Comédia Velha e Nova grega. A respeito da primeira produção, basta-nos evocar de leve o caso de um Fid-íp-ides n'As Nuvens de Aristófanes (Gripp 2009: 72), pois que essa personagem de jovem perdulário, justamente, de acordo com seu exorbitante amor pelos cavalos e pelas corridas e apostas a envolvê-los, apresenta no nome o radical grego para designar o mesmo animal (hyppos).

No domínio romano, ainda, sobejam no teatro plautino ou terenciano, segundo a característica galeria de tipos da Comédia Nova, personagens cujos nomes se encontram em estreita vinculação com seus traços físicos ou psíquicos:

"A título de exemplificação, retomamos, de Plauto (Cistellaria), a supracitada Ginásio (Gymnasium), cujo nome, em suas fontes gregas, na verdade designava um 'lugar para exercícios físicos sem roupa', mas, no contexto, evoca com ironia o métier de prostituta da moça, e sua mãe, Syra, claramente uma estrangeira de origem oriental. De Terêncio, por sua vez, encontra-se em A sogra a personagem de um pacato filho de família chamado Pânfilo, a partir de radicais gregos que significam, respectivamente, 'todo' e 'amigo' (Pânfilo = Amigo de todos, Boa-gente), bem como uma cortesã, por ele amada antes de casar-se, de nome Báquis; no último caso, pois, alude-se, a propósito dessa mulher inserida no mundo de uma profissão do prazer, ao nome do deus Baco, mítico libertador do homem na embriaguez dos sentidos". ${ }^{13}$

Isso posto, passaremos, nos tópicos seguintes, a exemplificar a incorporação a De re rustica III - além do fator da tradução de termos do latim para o grego - das definições vocabulares, da etimologia e do humor baseado nos trocadilhos com os nomes das personagens. Dessa maneira, esperamos poder indicar como os horizontes desta parte dos diálogos rústicos varronianos não se restringem à "ambiência mental" dos antigos

13 Trevizam 2010: 240-241. 
fundi rustici romanos, preenchendo-se também de elementos evocativos dos saberes-outros do polígrafo.

\section{b. A explicação de termos como ensaio da constituição de um léxico agrário em Varrão}

Na obra especializada de Gramática que é o De lingua Latina, Varrão valeu-se com alguma frequência do procedimento de elucidar expressões ${ }^{14}$ de importância para seu métier de teórico da língua pátria:

E assim ocorre a declinação das palavras: reto "homo", oblíquo "hominis", pois se declinou do reto. ${ }^{15}$

Nessa passagem, em diferenciação das ideias de (caso) reto ou oblíquo, ele recorre à noção comum, entre os antigos, de que as variantes morfossintáticas alheias ao nominativo, tomado como espécie de grau-zero linguístico para os nomes, eram, de algum modo, desvios em relação ao "ponto de partida". ${ }^{16}$ Note-se como, sobretudo, ao mencionar o (caso)

${ }^{14}$ Como se nota pelos exemplos que apresentamos nesta seção, Varrão não comenta palavras, propriamente, presentes em obras literárias alheias - como, supomos, fariam os "gramáticos" antigos a se pautarem estritos pelos ensinamentos de um Dionísio Trácio (cf. supra citação traduzida de parte da Téchnē Grammatichē do autor). Contudo, de algum modo, ocupa-se ele "gramaticalmente" de elucidações vocabulares atinente aos termos de suas obras; ainda, correspondendo os três diálogos do De re rustica a um construto com inegáveis configurações literárias, Varrão como que cumpre aproximadamente, em mais esse quesito e por explicar termos deles, tal parte das tarefas gramaticais de Dionísio, voltando-se, todavia, para comentar palavras presentes num texto artístico de sua própria lavra, não da de outros.

${ }^{15}$ Varrón 1990: 290: Itaque declinatur in uerbis: rectum homo, obliquum hominis, quod declinatum a recto (8.1.1 - minha tradução).

${ }^{16}$ Ernout; Thomas 2002: 7: «Le mot casus (lat. casus, de cado) adaptation du gr. ptōsis, cf. píptein 'tomber' - évoque l'idée d'une 'chute'. Il semble que, pour les Anciens, il y ait eu comparaison implicite avec un object, un stylet, par exemple, qui se fixe en tombant dans le sol. À la position verticale correspondait le nominatif ; casus rectus, ptōsis orthē; cf. Priscien, G.L.K. II, 184, I sqq.: nominatiuus... siue rectus... casus appellatur, ut stilum quoque manu cadentem rectum cecidisse possumus dicere. Les autres cas étaient des positions plus ou moins éloignés de la verticale: casus obliqui, ptōseis plágiai ». 
oblíquo como "desvio"/ "declinação" do ponto de partida, Varrão faz metalinguagem de um modo favorável ao bom recorte semântico de termos técnicos com que se terá de haver ao longo do De Lingua Latina.

Mutatis mutandis, algo similar é encontrado no excerto abaixo, a versar, como se vê, sobre um detalhe da apicultura que rotulamos como o dos "produtos das abelhas":

Chamam de "própolis" aquilo de que fazem um beiral junto à abertura em frente à colmeia, sobretudo no verão. Os médicos o empregam ainda com o mesmo nome nos emplastros, pelo que ainda se vende na Via Sacra mais caro que o mel. Chamam de "erithace" aquilo com que unem as extremidades dos favos entre si e difere do mel e do própolis; e assim, nele está a força de atraí-las. Por isso, aquele ramo ou algum outro objeto onde desejam que um enxame se assente besuntam com tal substância misturada à melissa. É o favo aquilo que moldam com muitas reentrâncias na cera, apresentando cada célula seis lados, tantos quantos os pés que a natureza deu a cada uma. ${ }^{17}$

Própolis, erithace e favo/ cera, como produtos de importância secundária para a economia rural antiga, pois, no tocante à apicultura, o mel, único adoçante conhecido dos antigos, rouba decisivamente a cena, merecem explicações capazes de desfazer eventuais ambiguidades no contexto de uma obra técnica - de agropecuária - na qual, inclusive, orienta-se para fazeres que se pretendem rendosos sob o aspecto econômico (Della Corte 1954: 93-94). E então, Varrão "lexicólogo" (ou comentador de expressões) da vida rústica ensina-nos acima donde provém o própolis [pró = "diante de"/ pólis = "cidade"(das abelhas) =, contextualmente, "colmeia"] e para que se presta e é comprado na Via Sacra, onde encontrar o dito erithace $e^{18} \mathrm{e}$

17 Varrão 2006: 512: Propolim uocant, e quo faciunt ad foramen introitus protectum ante aluum maxime aestate. Quam rem etiam nomine eodem medici utuntur in emplastris, propter quam rem etiam carius in sacra uia quam mel uenit. Erithacen uocant, quo fauos extremos inter se conglutinant, quod est aliut melle et propoli; itaque in hoc uim esse illiciendi. Quocirca examen ubi uolunt considere, eum ramum aliamue quam rem oblinunt hoc admixto apiastro. Fauus est, quem fingunt multicauatum e cera, cum singula caua sena latera habeant, quot singulis pedes dedit natura (3.16.23-24 - minha tradução).

${ }^{18}$ Segundo comentário de Heurgon a essa passagem de De re rustica III, Varrão, na verdade, apropria-se inadequadamente desse termo, já presente em 
como tirar proveito de sua atração sobre as abelhas e, enfim, ponto menos obscuro da "lição", o que sejam os favos.

Semelhante postura explicativa, lembramos, não se restringe à passagem mencionada do De re rustica, podendo-se citar outras ocorrências. Por conseguinte, não nos parece excessivo dizer, a respeito dessa prática "gramatical" do autor, que ele elabora e compila, especificamente no livro III da obra, toda uma série de comentários lexicais atinentes ao tema da uillatica pastio, cujo interesse também está, para nós, em consistir numa tentativa de compreender o universo rústico em sua dimensão vocabular.

\section{c. Apresentação de duas passagens "etimologizantes" de De re rustica III}

Já no proêmio do livro III do De re rustica encontramos uma passagem "etimologizante" complexa a envolver o topônimo Thebae, nome de certa cidade grega da Beócia:

Ainda, não menos o nome da cidade de Tebas mostra que o campo é mais antigo, pois pelo tipo do campo, não pelo nome do fundador, ele the foi posto. Com efeito, a língua antiga e os eólios da Beócia, na Grécia, chamam as colinas de "tebae" sem aspirar, e, entre os sabinos, para onde vieram da Grécia os pelasgos, ainda agora se fala assim; há um vestígio disso, no território sabino e na via Salária, não longe de Reate: um declive de uma milha ser chamado de "tebae". 19

Aristóteles: «Quant à l'erithace, il s'agit d'une confusion de Varron. Le mot désigne chez Aristote (H.A. V, 554a 17) et chez Pline 11, 17, la matière brute dont l'abeille fera le miel. Le pollen des fleurs se met sur les poils qui couvrent le corps des abeilles. Grâce à l'action de la seconde paire de pattes, le pollen est collecté dans des boulettes et déposé dans un creux de la troisième paire de pattes. L'erithace, qu'on appelle parfois 'nourriture des abeilles', sert en fait à nourrir les larves et les jeunes abeilles, les adultes se nourrissent de miel » (Varron 1997: 101).

19 Varrão 2006: 424: Nec minus oppidi quoque nomen Thebae indicat antiquiorem esse agrum, quod ab agri genere, non a conditore nomen ei est impositum. Nam lingua prisca et in Graecia Aeolis Boeoti sine afflatu uocant collis tebas, et in Sabinis, quo e Graecia uenerunt Pelasgi, etiam nunc ita dicunt, cuius uestigium in agro Sabino uia Salaria non longe a Reate miliarius cliuus cum appellatur tebae (3.1.6-7 - minha tradução). 
$\mathrm{Na}$ introdução prévia a este mesmo livro, Varrão iniciara uma discussão laudatória sobre a proeminência dos campos, quando cotejados com as cidades, em importantes aspectos. Assim, além de julgarem os ancestrais dos romanos de seu tempo que os agricultores levam existência "pia e útil" e são os derradeiros representantes da "estirpe de Saturno", busca-se comprovar por certos indícios corresponder o modo de vida camponês a um estágio anterior na escala de desenvolvimento humana ("Nem é de admirar, pois a natureza divina deu os campos, mas a arte humana edificou as cidades"). ${ }^{20}$

Isso justifica a recorrência ao instrumental etimológico em jogo para fazer-se mais fiável no ponto da venerável antiguidade dos campos. Dessa maneira, mencionando acreditar que Thebae, como topônimo urbano, provém não do nome de um fundador qualquer, ${ }^{21}$ mas das próprias condições geográficas existentes no terreno onde se encontra, caracterizado, explica, pela presença de colinas, Varrão parece querer dizer que uma denominação espacial prévia, apenas vinculada a elementos de paisagem e não culturais, portanto, passara-se posteriormente para a cidade no momento histórico de construí-la. Com isso, já havendo supostamente o nome e a "coisa" designada antes desse nascimento urbano, o autor ensaia uma tentativa de remontar, na língua grega, ao étimo, ${ }^{22}$ ao "verdadeiro significado" do topônimo helênico sob mira perscrutadora na passagem.

O prosseguimento do trecho, ainda, revela intentos de reforço da constatação levantada, vale dizer, da pré-existência de campos com colinas na Beócia (ou dos campos em geral) a quaisquer aglomerados urbanos. Assim, julgando o autor ter sido no passado o país itálico dos sabinos "colonizado" por "pelasgos" (= gregos), teriam eles trazido de sua pátria o costume de denominarem zonas acidentadas de terreno com recorrência ao

${ }^{20}$ Varrão 2006: 422: Nec mirum, quod diuina natura dedit agros, ars humana aedificauit urbes (3.1.4 - minha tradução).

${ }^{21}$ Como, lendariamente, Roma de "Rômulo", seu mítico fundador. Sobre tentativas de etimologizar com maior rigor, porém, cf. Brandão 1993: 259260: "Roma, nome da capital do Lácio, é talvez de origem etrusca, mas se lhe desconhece o sentido, DIELL., 576. Carnoy, todavia, DEMG., 179, propõe várias hipóteses para se desvendar o mistério da etimologia da Vrbs e entre elas parece inclinar-se para aquela em que Roma proviria do etrusco Rumon, um dos nomes do rio Tibre e, neste caso, o topônimo significaria 'a rápida, a tumultuosa', mas a hipótese é contestada".

${ }^{22} \mathrm{Cf}$. supra nota 9. 
mesmo termo "não aspirado" (th-) tebae. Hooper e Ash, responsáveis pela edição e tradução de Harvard desta obra varroniana, observam em nota que, apesar da inegável assimilação, desde tempos longínquos, de numeroso vocabulário grego por tantos povos itálicos (entre eles, os etruscos), tais explicações não parecem defensáveis no tocante, especificamente, à suposta denominação sabina para declives como os descritos aqui, pois que o termo em questão sequer se encontraria documentado, exceto pelo uso na passagem sob nosso olhar (Varrão 2006: 425).

Na sequência, coincidentemente, a passagem que transcrevemos também se vincula à focalização de uma palavra do léxico rústico com conotações espaciais:

Enquanto isso, torna Ápio: perguntou-nos, e nós a ele, o que se tinha dito e feito. Ápio disse: "Segue-se o ato do segundo tipo, que costuma ser um anexo da casa de campo, e foi chamado, pelo antigo nome, em razão de uma certa parte, "leporarium". Com efeito, não se fecham nele, num bosque, apenas lebres, como outrora numa jeira de campo ou duas, mas ainda cervos ou cabras em muitas jeiras". ${ }^{23}$

Com efeito, nos tempos de Varrão, um leporarium (em possível tradução, "criadouro") deixara de identificar-se, por força, com o exclusivo abrigo das lebres (lepores, em latim), para alargar-se e acolher animais de maior porte como cervos e caprinos. Assim, aludindo à motivação do nome do recinto "em razão de uma certa parte", vê-se que o autor já tem em mente etimologicamente - como quase de imediato se esclarece ao falar ele com clareza das "lebres" - a origem mais restrita desse compartimento rústico.

Devemos observar, em conformidade com o amiúde notado aggiornamento do fundus rusticus varroniano no terceiro e último livro da obra, que a intensificação das criações em sua época - séc. I a.C. - coaduna-se com a profunda mudança das tradicionais funções antes destinadas ao campo em Roma antiga. Dessa forma, de corriqueiro espaço interacional de

${ }^{23}$ Varrão 2006: 488: Interea redit Appius, et percontati nos ab illo et ille a nobis, quid esset dictum ac factum. Appius, Sequitur, inquit, actus secundi generis adficticius ad uillam qui solet esse, ac nomine antico a parte quadam leporarium appellatum. Nam neque solum lepores in eo includuntur silua, ut olim in iugero agelli aut duobus, sed etiam cerui aut capreae in iugeribus multis (3.12.1 - minha tradução). 
cidadãos identificados com o duplo papel de soldados-agricultores, a zona rural povoa-se de cativos a partir, sobretudo, do final das Guerras Púnicas, assumindo, deste ponto em diante, papéis gradativamente afins aos do comércio em larga (e rendosa) escala de produtos rústicos. ${ }^{24}$ Isso significa, no contexto que aqui nos interessa, assistirmos à inadequação do nome leporarium às suas novas funções - de abrigo aumentado de cabras e, até, cervos - como indício do decisivo refinamento dos padrões de consumo na Roma de fins da república: assim, expandir em todos os sentidos as potencialidades produtivas de semelhante espaço equivale a buscar atender às crescentes e novas demandas materiais (Della Corte 1954: 93-94) de uma cidade decisivamente firmada como exigente metrópole em nível mundial.

\section{d. Recurso ao humor baseado nos trocadilhos com os nomes das personagens}

Como dissemos acima, a derivação da comicidade dos trocadilhos e da própria onomástica das personagens envolvidas em comédias ou outros tipos de produção literária antiga corresponde a algo bastante difundido nas letras greco-romanas. Em Varrão, que, inclusive, aproxima textualmente seu fazer artístico no De re rustica da produção dramática clássica, ${ }^{25}$ podemos dizer que a recorrência a esses efeitos, tributária das próprias origens camponesas do povo e de tantas instituições de Roma (Marouzeau 1946: 144), reveste-se, além do lado humorístico, de funções ordenadoras

${ }^{24}$ Trevizam 2006: 18-19: “A passagem do terceiro para o segundo século a.C., assim, assinala na história agrária romana uma era de 'revolução': assistimos, nessa época, ao surgimento de um sistema produtivo decisivamente voltado para a intensa comercialização de excedentes. É preciso lembrar que a derrota da potência representada por Cartago significou para Roma vantagens como a anexação das possessões da ex-inimiga, o ganho de seu espaço comercial no mediterrâneo e a abertura para o fluxo escravista em larga escala".

25 Trevizam 2010: 245: "Referimo-nos, especificamente, aos termos pars e actus (papel e ato), por vezes explicitados na tessitura da obra em contextos metalinguísticos, ou seja, de comentário das personagens sobre a própria interação nos diálogos e sobre o andamento dos mesmos: a propósito de De re rustica II, então, encontramo-los, por um lado, em 5, 2 e 10, 1 e, por outro, em 5, 2/ 8, 1 e $10,1 "$. 
do discurso técnico internamente ao terceiro (ou aos demais) diálogo da mesma obra:

Assim fomos, e chegamos à Villa. Lá, encontramos o áugure Ápio Cláudio sentado nos bancos para estar pronto a ser consultado, se a necessidade de algum modo o exigisse. Estavam sentados à sua esquerda Cornélio Mérula, com ancestrais cônsules, e Fircélio Pavão reatino; à direita, Minúcio Pica e M. Petrônio Passer. Tendo-nos nós aproximado dele, Áxio disse a Ápio, sorrindo: "Tu nos recebes em teu viveiro de aves, onde estás sentado entre pássaros?"26

Temos, no trecho citado, a hora correspondente ao começo efetivo do diálogo entre as personagens, ao longo do qual alternar-se-ão, a fim de transmitirem os saberes referentes à uillatica pastio (criação ornamental ou comercial de pequenos animais nos entornos das uillae rusticae romanas) que possuem. Como se vê, o interlocutor identificado com Áxio interpela o áugure Ápio nesse momento para encetar as conversas desencadeadoras da interação técnica entre os presentes, sintomaticamente recorrendo, com humor, a um jogo de palavras com o nome de alguns. Na verdade, Merula, Pauo, Pica e Passer do original latino remetem-nos todos a espécies de aves naquele idioma ("melro", "pavão", "pega" e "pardal”), de maneira que se justifica, figurando Áxio tomar tais antropônimos por substantivos comuns, considerar a fortuita reunião de tantos "pássaros" um "viveiro" (ornithon, segundo a letra do texto). Em trecho mais adiantado do mesmo livro III do De re rustica, ${ }^{27}$ a personagem de Fircélio Pavão reatino, especi-

${ }^{26}$ Varrão 2006: 428: Itaque imus, uenimus in uillam. Ibi Appium Claudium augurem sedentem inuenimus in subselliis, ut consuli, siquid usus poposcisset, esset praesto. Sedebat ad sinistram ei Cornelius Merula consulari familia ortus et Fircellius Pauo Reatinus, ad dextram Minucius Pica et M. Petronius Passer. Ad quem cum accessissemus, Axius Appio subridens, Recipis nos, inquit, in tuum ornithona, ubi sedes inter aues? (3.2.2 - minha tradução).

${ }^{27}$ Varrão 2006: 458: Axius, De pauonibus, inquit, libere licet dicas, quoniam discessit Fircellius, qui, secus siquid diceres de iis, gentilitatis causa fortasse an tecum duceret serram. Quoi Merula, De pauonibus nostra memoria, inquit, greges haberi coepti et uenire magno. - Áxio disse: "Podes falar livremente dos pavões, já que Fircélio partiu, pois, se dissesses algo em atrito sobre eles, talvez brigasse contigo por causa da família". Mérula disse a ele: "Sobre os pavões, pelo que me lembro, os bandos deles no começo eram mantidos e vendidos caro”. - (3.6.1 minha tradução). 
ficamente, torna-se alvo, em sua ausência, de novo gracejo motivado por semelhantes afinidades entre o plano da onomástica latina e o de várias espécies naturais. Nesse contexto renovado, como se há de iniciar a fala técnica a respeito da criação de pavões, Áxio encoraja Mérula a fazê-lo sem receio, pois Fircellius ( $P$ auo), que talvez se poderia zangar com algo dito em desacordo sobre seus "parentes", ausentara-se, deixando naquela ocasião os assentos da Villa Publica a enquadrarem espacialmente o diálogo em pauta...

Embora, neste caso - como, de resto, ocorrerá de maneira aproximada com Mérula em trechos de abordagem da avicultura! -, não tenha cabido ao interlocutor mais conveniente (Pauo = "Pavão"), por seu nome, tratar dessa peculiar criação de aves, o efeito por vezes ocorre ao longo de todo o De re rustica, resultando, nos melhores casos, em precisos "rótulos" a designarem, pelo nome do eventual interlocutor... aquilo mesmo de que falará ao ser-lhe concedida a palavra. De qualquer modo, sempre se patenteia a astúcia varroniana de concentrar, em cada diálogo do De re rustica, personagens com nomes em grande medida afins a cada grande universo técnico da agropecuária abordado, seja ele o do cultivo, ${ }^{28} \mathrm{o}$ da pecuária ${ }^{29}$ ou, como vimos, o da uillatica pastio: afinal, assim se consegue, parecenos, além da harmonização entre mais de um aspecto constitutivo da obra, a descontraída leveza advinda do próprio inusitado da "coincidência" de afluírem, para conversar com humor de várias técnicas agrárias possíveis, justo homens a apresentarem nexos onomásticos estreitos com as mesmas.

\section{e. A tradução ao grego como meio de acuidade técnica em De re rustica III}

Segundo observação de Cesidio de Meo (De Meo 1986: 50ss.), a presença dos helenismos na língua de Roma destaca-se, além de no âmbito literário, também no dos linguajares técnicos, segundo os temos, em Varrão, como variante do latim utilizada para compor o De re rustica. Isso se explica pelo importante desenvolvimento helênico em tantas áreas das

${ }^{28}$ Em De re rustica I, surgem nomes de interlocutores como Stolo ("Estolão"), a designar, como substantivo comum, o "ladrão", ou broto surgido da planta no nível do solo.

${ }^{29}$ Em De re rustica II, temos Vaccius, Equiculus, Scrofa (respectivamente, relacionados aos substantivos comuns uacca, "vaca", equus, "cavalo", e scrofa, "porca")... 
"ciências" - inclusive na medicina, amiúde agregada às páginas dos escritos rústicos romanos, a exemplo do De agri cultura de Catão Censor e do De re rustica varroniano mesmo -, tendo-se dado desde épocas longínquas aatravés dos contatos de Roma com os gregos da Itália meridional, b- com adaptações de sua cultura pelas mãos prévias dos etruscos e, enfim, c- de certo intercâmbio "livresco", ao se assimilar, propriamente, patrimônio linguístico que parece oriundo de zonas de "alta cultura", não da mera praticidade quotidiana.

Propomos, nesta brevíssima seção, o olhar para os helenismos do livro III do De re rustica em algumas ocasiões nas quais se identificam com operações "tradutórias" de termos da vida rústica: assim, em 3.9.18, menciona-se a- que o nome das "galinhas africanas" naquele idioma é meleagrides $;{ }^{30} \mathrm{em} 3.10 .1$, apresentam-se as aves que repartem seu tempo entre a terra e a água como pertencentes a uma categoria "anfíbia", dizendose, ainda, b- que a granja onde são engordados gansos recebe o peculiar nome de chenoboscion (correspondendo khênoboskêion à forma original); $; 1$ em 3.16.10-11, c- dão-se como alternativas para o nome botânico apiastrum ("melissa") as formas helenizantes meliphyllon, melissophyllon e melittae$n a: 32$ pouco depois, em 3.16.12, d- menciona-se como designação alternativa (na fala de "alguns" - alii) para o apiário "melitrophium". ${ }^{33}$

Se em (a), (c) e (d) as expressões adotadas sempre encontram um correspondente preciso "à mão" no latim (gallinae Africanae, apiastrum e mellarium), vale dizer, consagrado pelo uso, o mesmo não ocorre em (b), pois, na verdade, ter-se-ia desta feita de recorrer a um circunlóquio para dar conta de expressar a ideia contida no termo grego ("granja para engorda de gansos", em vez de um banal e impreciso auiarium - "viveiro/ criadouro de aves"). ${ }^{34}$ De todo modo, o cuidado de Varrão em tornar-se tecnicamente mais preciso pela recorrências a tais vocábulos à grega patenteia-se aqui quer quando os apresenta como alternativa para algo corrente no idioma

${ }^{30}$ Varrão 2006: 480: Os tradutores norte-americanos dão, para o termo, a transcrição helênica, no singular, meleagrís.

${ }^{31}$ Varrão 2006: 482.

${ }^{32}$ Segundo explicações dadas por Guiraud, respectivamente "folha de mel", "folha das abelhas" e "erva das abelhas", no último caso, encontrando-se a palavra citada no grego Nicandro, Ther. 554 melíttaina (Varron 1997: 102).

${ }^{33}$ Varrão 2006: 504.

${ }^{34} \mathrm{O}$ termo específico e correlato anserarium apenas se documenta depois, na obra de Columela, autor do século I d.C. (Saraiva 1993). 
pátrio, quer quando se vale deles como quem cobriria uma lacuna lexical no mesmo ambiente linguístico. Afinal, com simplesmente "desfazer ambiguidades" pelo reforço do "mesmo" ou com, até, delimitar, baseando-se no idioma estrangeiro em pauta, uma zona significativa de menor relevo vocabular no próprio, ele se mostra invariável cuidador do léxico referente ao domínio especializado de cujos permeáveis limites nos fala.

\section{f. Conclusão}

Tais modos varronianos de cuidado com a palavra, esperamos, comprovam-nos a tese inicial de ser ele, mesmo quando aborda saberes eminentemente práticos como os da uillatica pastio, um escritor atento e cioso da dimensão vocabular miúda do De re rustica III. Nesse sentido, não só o pequeno público de fato interessado nas vicissitudes da lida agrária em Roma antiga tem a ganhar pela leitura desta (saborosa) obra antiga, mas, ainda, todos os entusiastas e cultores da língua do Lácio.

\section{Referências Bibliográficas}

Agache, S. (1998), « Construction dramatique et humour dans le 'Traité d'agriculture' de Varron », in Trédé, M.; Hoffmann, P. (ed.), Le rire des anciens. Paris: Presses Universitaires de l'École Normale Supérieure, 201-230.

Bailly, A. (s.d.), Abrégé du Dictionnaire Grec-Français. Paris, Hachette.

Blank, D. (2008), "Varro and the epistemological status of etymology", Histoire épistémologie langage 30.1. Paris: 49-73.

Brandão, J. (1993), Dicionário mítico etimológico. Mitologia e religião romana. Petrópolis/ Brasília, Vozes/ Edunb.

Cato, Varro (2006), On agriculture. With an English translation by W. D. Hooper, revised by H. B. Ash. Cambridge, Mass./ London, Harvard University Press: 422-529.

Codoñer, C. ed. (2007, 2a . ed.), Historia de la literatura latina. Madrid, Cátedra: 755-772.

Della Corte, F. (1954), Varrone. Il terzo gran lume romano. Genova, Publicazioni dell'Istituto Universitario di Magistero.

De Meo, C. (1986, 2a . ed.), Lingue tecniche del latino. Bologna, Pàtron: 32-58. 
ERnout, A.; Thomas, F. (2002), Syntaxe latine. Paris, Klincksieck.

Gripp, B. (2009), “A língua presa de Fidípides”, Nuntius Antiquus 3. Belo Horizonte: 69-84 - acessado pela internet em 20/ 01/ $2011<\mathrm{http}: / /$ www.letras.ufmg.br/nuntius/data1/arquivos/003.06-Bruno69-84. pdf>

Heurgon, J. (1950), « Style de Varron dans les 'Res rusticae' », Revue de Philologie 24. Paris: 57-71.

Lyons, J. (1979), Introdução à Linguística teórica. Tradução de Rosa Virgínia Mattos e Silva e Hélio Pimentel. São Paulo, Companhia Editora Nacional/ Edusp.

Marouzeau, J. (1946), Traité de stylistique latine. Paris, Les Belles Lettres. Miguel, L. A. (2000), Varrón. Madrid, Clásicas.

Pereira, M. A. (2000), Quintiliano gramático. O papel do mestre de gramática na "Institutio oratoria". São Paulo, Humanitas.

Plauto (2004), Amphitruo; Asinaria; Aulularia; Bacchides. A cura di Ettore Paratore. Roma, Tascabili Economici Newton.

Poccetti, P. (2009), «Un animal au centre du monde. Le cochon dans

l'Antiquité italique et romaine », Schedae 8.1. Caen: 125-141 acessado pela internet em 20/ 01/ $2011<$ http://www.unicaen.fr/ services/puc/ecrire/preprints/preprint0082009.pdf.>

Robins, R. H. (1983), Pequena história da Linguística. Tradução de Luiz Martins Monteiro de Barros. Rio de Janeiro, Ao Livro Técnico.

Saraiva, F. R. S. (1993, 10a . ed.), Novíssimo dicionário Latino-português. Rio de Janeiro/ Belo Horizonte, Garnier.

Traglia, A. (1985), "Le 'Res rusticae' di Varrone come opera letteraria", Cultura e scuola 94. Roma: 89-97.

Trevizam, M. (2009), “A face 'gramatical' de Varrão em 'De re rustica' II”, Aletria 19.3. Belo Horizonte: 89-101.

Trevizam, M. (2002-2003), "Das especulações 'etimológicas' antigas: as contribuições de Platão e Varrão", Classica 15.16. São Paulo: 179188.

TrevizAm, M. (2006), Linguagem e interpretação na literatura agrária latina. Tese de doutorado inédita, submetida ao Departamento de Linguística do IEL-UNICAMP como parte dos requisitos para obtenção do título de Doutor em Linguística/ Latim. Campinas, IELUNICAMP.

Trevizam, M. (2010), “O 'De re rustica' II de Varrão reatino e a comédia greco-romana: analogias”, Caligrama 15.1. Belo Horizonte: 229-251 
- acessado pela internet em 20/ 01/ $2011<$ http://www.letras.ufmg.br/ caligrama>

VARrón (1990), De lingua Latina. Introducción, traducción y notas de Manuel-Antonio Marcos Casquero. Barcelona/ Madrid, Ánthropos/ Ministerio de Educación y Cultura: 8-51.

VARRON (1997), Économie rurale. Livre III. Texte établi, traduit et commenté par Charles Guiraud. Paris, Les Belles Lettres. 